\title{
壁関数を用いた格子ボルツマン法による乱流熱流動解析
}

\section{Lattice Boltzmann Wall-Modeled Simulation of Turbulent Heat Transfer}

\section{○学 藤原 一樹（阪府大） 正 桑田 祐丞（阪府大） 正 須賀 一彦（阪府大） \\ Kazuki Fujiwara ${ }^{1}$, Yusuke Kuwata ${ }^{1}$, and Kazuhiko Suga ${ }^{1}$ \\ ${ }^{1}$ Osaka Prefecture University, 1-1 Gakuencho, Naka-ku, Osaka 599-8531, Japan}

\begin{abstract}
This study assesses applicability of wall-modelled large eddy simulations of turbulent heat transfer by the lattice Boltzmann method. For the implementation, virtual grid points that prescribes the weakly slip velocity conditions are introduced in order to enforces the wall-shear stress to wall-adjacent nodes, and the wall-heat flux is given to the nodes as well. For the validation, heat transfer in a turbulent channel flow at friction Reynolds numbers up to 8,000 is simulated. It is confirmed that the developed method reasonably predicts the mean velocity and temperature profiles at various Reynolds numbers, and the grid independence of the simulation results is also confirmed.
\end{abstract}

Key Words: Lattice Boltzmann, wall-function, turbulent heat transfer, large eddy simulation

\section{1. 緒言}

計算機技術の飛躍的な進歩により，大きなスケールの乱流渦を直接時空間的に解像するラージ・エディ・シミュレー ション (LES: Large Eddy Simulation) による大規模な解析が容易になりつつあり, 産業界では高精度な LES 解析の応 用が期待されている. しかし壁面近傍においては, 微細な渦構造を捉えられるほどの非常に細かい計算格子を設定す る必要があり, 高レイノルズ数乱流における応用解析は未だ困難である. そこで壁面モデルを適用することで, 壁面近 傍に粗い計算格子を用いた LES 解析が注目を浴びている. その一方で, 格子ボルツマン法（LBM: Lattice Boltzmann Method）は, 格子生成の必要が無く, 複雑流路形状の表現能力が高く, 計算効率の高い解析が可能であるため, 有限 差分法や体積法に代表される Navier-Stokes ソルバーに替わる数值解析手法として注目されている. しかし, LBM に壁 関数法を組み合わせた LES 解析に関しては, その実装方法に関する十分な検討はされておらず, 速度・温度場におけ る性能に関して十分な精度検証が行われていない, そこで, 本研究では, LBM に壁関数法を組み合わせる新たな手法 を提案し，乱流熱流動場における検討を行う。

\section{2. 解析方法}

\section{1 三次元 27 方向速度多緩和時間格子ボルツマン法}

本研究では, 速度場に対して三次元 27 方向速度多緩和時間格子ボルツマン法(1)を用いた. 密度分布関数 $\boldsymbol{f}$ の時間 発展方程式は次のように表される.

$\left|\boldsymbol{f}\left(x+\xi_{a} \delta t\right)\right\rangle-|\boldsymbol{f}(x, t)\rangle=-\boldsymbol{M}^{-1} \widehat{\boldsymbol{S}}\left(|\boldsymbol{m}(x, t)\rangle-\left|\boldsymbol{m}^{e q}(x, t)\right\rangle\right)-|\boldsymbol{F}(x, t)\rangle$.

ここで, $|f\rangle$ は $|f\rangle=\left(f_{0}, f_{1}, \cdots, f_{26}\right)^{\mathrm{T}}$ を表し,$\delta t$ はタイムステップ, $\xi_{\alpha}$ は離散速度ベクトル, $\boldsymbol{F}$ は外力項である. また, $\boldsymbol{M}$ は $27 \times 27$ の変換マトリクス, $\widehat{\boldsymbol{S}}$ は緩和マリリクスであり, モーメント $\boldsymbol{m}$, 平衡モーメント $\boldsymbol{m}^{e q}$ はそれぞれ,

$$
|\boldsymbol{m}\rangle=\boldsymbol{M}|\boldsymbol{f}\rangle,\left|\boldsymbol{m}^{e q}\right\rangle=\boldsymbol{M}\left|\boldsymbol{f}^{e q}\right\rangle,
$$

のように表される.

\section{2 三次元 19 方向速度単緩和時間正規化格子ボルツマン法}

温度場の解析には, 三次元 19 方向速度単緩和時間正規化格子ボルツマン法(2) (D3Q19 regularized SRT - LBM) を 用いた. 非熱流体モデルにおける内部エネルギー密度分布関数 $\boldsymbol{g}$ の時間発展方程式は, 以下のように表される.

$\left|\boldsymbol{g}\left(\boldsymbol{x}+\boldsymbol{\xi}_{\alpha} \delta t, t+\delta t\right)\right\rangle=\left|\boldsymbol{g}^{e q}(\boldsymbol{x}, t)\right\rangle+\left(1-\frac{1}{\tau_{g}}\right)\left|\overline{\boldsymbol{g}^{n e q}}(\boldsymbol{x}, t)\right\rangle$. 
No.19-303 日本機械学会熱工学コンファレンス 2019 講演論文集 [2019.10.12-13, 名古屋] CopyrightC2019 一般社団法人 日本機械学会

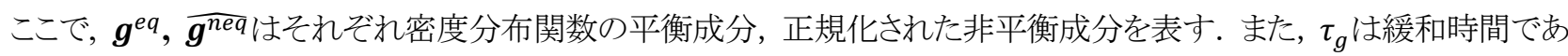
る.

\section{3 壁関数法}

これまで, 複雑流動場における差分 LES 解析への壁関数法の導入法に関して多くの検討がされてきた. 有限差分法 に壁関数法を導入する際には, 壁関数により求めた壁面せん断応力を与えて, 質量 ・運動量保存則の保存式を陽 的に解くが, 格子ボルツマン法では壁面ノードから流体ノードに向から複数の分布関数成分をすべて適切に与える必 要がある. 特に, 保存則を陽的に解かない LBM では, 質量 ・運動量保存則の保存則を満たしつつ, 適切な壁面せ 几断応力を与える分布関数を規定するのは困難を極める. そこで, 本研究では, 有限差分法において, すべり速度を 与えることで壁面せん断応力の修正を行う手法(3)の代わりとして, 壁面内部に仮想ノード点を用意し, 運動量 ・質量保 存則を満たす滑り速度を与えつつ, 壁面隣接ノードに適切な壁面せん断応力を与える方法を提案する. 以下に詳細に ついて説明する. 図 1 に壁面近傍におけるノード点配置を示す. 点 $i$ は壁面隣接ノード点であり, 点 $i-1, i-2, \cdots$, $i-n$ が壁面内部に埋め込む仮想ノード点を示しており, 壁面は点 $i$ と点 $i-1$ の中心に位置し, 仮想壁を点 $i-n$ に設置 した. 流体計算は壁面に埋め込まれた仮想ノードに関しても行い, 隣接ノード点 $i$ には壁関数法により計算された壁面 せん断応力を付与する. ノード点 $i$ に付与する壁面せん断応力に関しては, ノード点 $i+1$ における壁面接線方向速度 が対数速度分布 (Musker の式(4)) に整合する摩擦速度をニュートン法により求め, その摩擦速度から壁面せん断応力

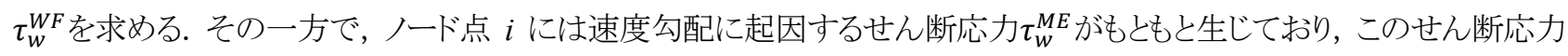
はモーメンタムエクスチェンジ(5)を用いて評価する. ノード点 $i$ における壁面せん断応力を壁関数法によって求めたせん 断応力に置き換えるために, 体積力 $F_{W F}$ を

$F_{W F}=\frac{1}{\rho \Delta}\left(-\tau_{w}^{M E}+\tau_{w}^{W F}\right)$,

として計算し, 支配方程式(1)に付与する. ここで, $\Delta$ は格子幅を表す. さらに, 本手法では壁面隣接ノード点 $i$ におい

て, 仮想壁からの垂直方向の速度による運動量フラックスを打ち消寸ための体積力 $F_{F X}$ を

$F_{i, F X}=\frac{c}{\Delta} u^{\mathrm{N}} u_{i}^{\mathrm{T}}$,

とモデル化し，支配方程式(1)に付与する. ここで, $C$ はモデル定数, $u^{\mathrm{N}}, u_{i}^{\mathrm{T}}$ はそれぞれ壁面垂直方向速度, 接線方向 速度を表しており, $C=0.1$ とした.

温度場に関しては，速度場同様に仮想ノード点まで支配方程式を解く.ノード点 $i-n$ の点に断熱境界条件を与え， 壁面隣接ノード点 $i$ には Kaderの経験式(6)によって求めた壁面熱流束をソース項に加えることで, 壁法則に基づいた壁 面熱流束を与えた解析を行う.

\section{3. 数值解析}

\section{1 計算条件}

図 2 に示寸二次元平板チャネルにおける乱流熱流動の数值解析を行った. 計算領域 $3 H(x) \times H(y) \times 1.5 H(z)$ として, チャネル高さ $H$ に対して計算格子を $N Y=40,60,80$ として計算を行った. 半チャネル高さと壁面摩擦速度 $u_{\tau}$ を 代表值とする摩擦レイノルズ数 $\mathrm{Re}_{\tau}$ は $1000,4000,8000$ とした. 速度場では流入流出面に一定圧力差を与え, 境界条件 は壁面上で滑り無しとし, 流れ方向およびスパン方向は周期境界条件を用いた. 温度場に関しては, 壁面熱流束を一 定しして与え, 主流方向に対して線形的に変化するバルク温度からの変動温度 $\Theta$ を解いた. また, 流体のプラントル数 は 1.0 として解析を行い, サブ・グリッド・スケールモデルとして Shear-improved Smagorinsky モデル(7)を適用した. 本解 析では仮想ノード点として, 壁面内部に 2 点用意しており, 壁面垂直方向に対して格子点 $N Y+4$ 点用意した.

\section{2 結果と考察}

図 3-5 は, チャネル高さ $H$ に対する格子数 $N Y=40,60,80, \mathrm{Re}_{\tau}=1000,4000,8000$ における主流方向速度分布と 対数速度分布を比較した. 対数速度分布は 
$U^{+}=\frac{1}{\kappa} \ln \left(y^{+}\right)+B$

と表され, $\kappa=0.4, \mathrm{~B}=5.0$ とした. 本研究では開発した手法は, レイノルズ数によらず平均速度分布は対数速度分布と 良く一致しており, 計算結果の格子依存度も少ないことも確認できる.

次に，平均温度分布と対数温度分布

$\Theta^{+}=2.12 \ln \left(y^{+} \operatorname{Pr}\right)+\left(3.85 \operatorname{Pr}^{1 / 3}-1.3\right)^{2}$,

を比較した結果を図 6-8 に示す. 速度場同様に, 壁関数法により得られた温度分布は対数則と良く一致しており, 計 算結果の格子依存度も少ないことも確認できる.

\section{4. 結言}

本研究では, 格子ボルツマン法と壁関数法を組み合わせる新たな手法として, 仮想ノード点を用いて壁面すべり速 度・温度を与えて壁面せん断応力・熱流束を適切に与える手法の開発を行った. 二次元平板チャネルでその有効性を 議論し，計算格子に大きく依存することなく，本手法は速度・温度場ともに対数則を再現することを確認した。

\section{参考文献}

(1) Suga, K., et al., A D3Q27 multiple-relaxation-time lattice Boltzmann method for turbulent flows, Computers \& Mathematics with Applications, 69 (2015), 518-529.

(2) Suga, K., et al., Modelling turbulent and dispersion heat fluxes in turbulent porous medium flows using the resolved LES data, International Journal Heat Mass Transfer , 68 (2017), 225-236.

(3) Y. Bazilevs, et al., Weak Dirichlet Boundary Conditions for Wall-Bounded Turbulent Flows, International Journal of Heat and Mass Transfer, 196 (2007), 4853-4862.

(4) Musker, A. J., Explicit Expression for the Smooth Wall Velocity Distribution in a Turbulent Boundary Layer, AIAA Journal, 17 (1979), 655-657.

(5) Chen, Y., et al., Momentum-exchange method in lattice Boltzmann simulations of particle-fluid interactions, Physical Review E, 88(1) (2013), 013303.

(6) Kader, B. A., Temperature and concentration profiles in fully turbulent boundary layers, International Journal of Heat and Mass Transfer, 24(9) (1981), 1541-1544.

(7) Lévêque, Emmanuel, et al., Shear-improved Smagorinsky model for large-eddy simulation of wall-bounded turbulent flows, Journal of Fluid Mechanics, 570 (2007), 491-502.

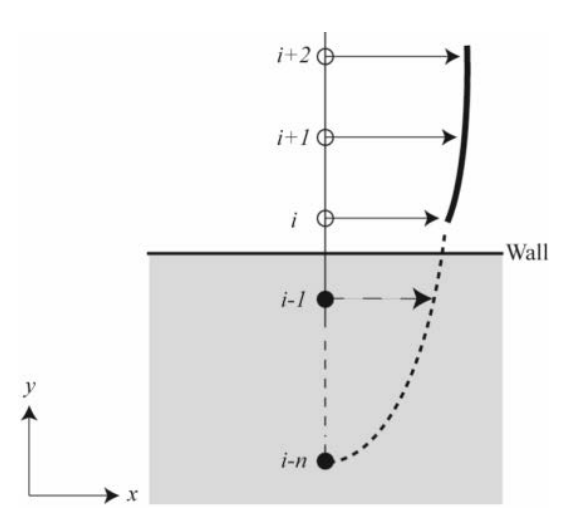

Fig.1 Grid arrangement near a wall.

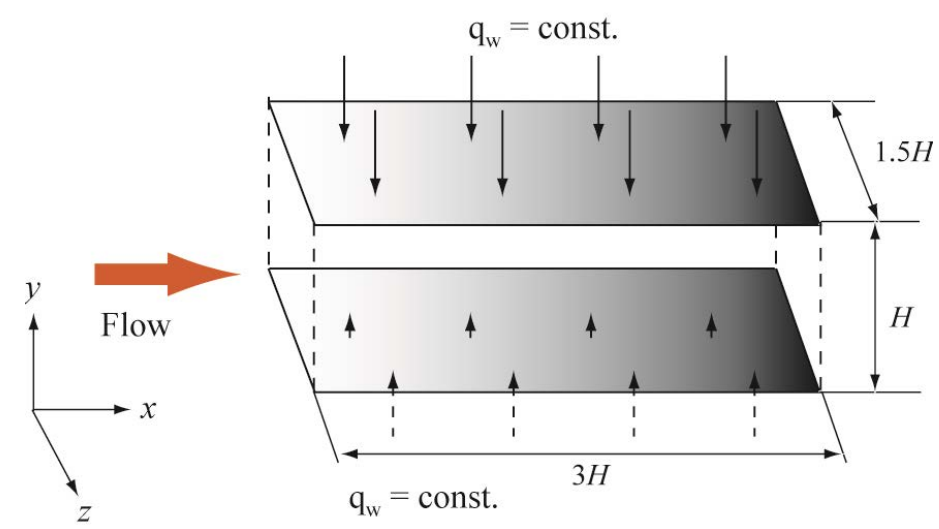

Fig. 2 Computational geometry of a turbulent channel flow. 


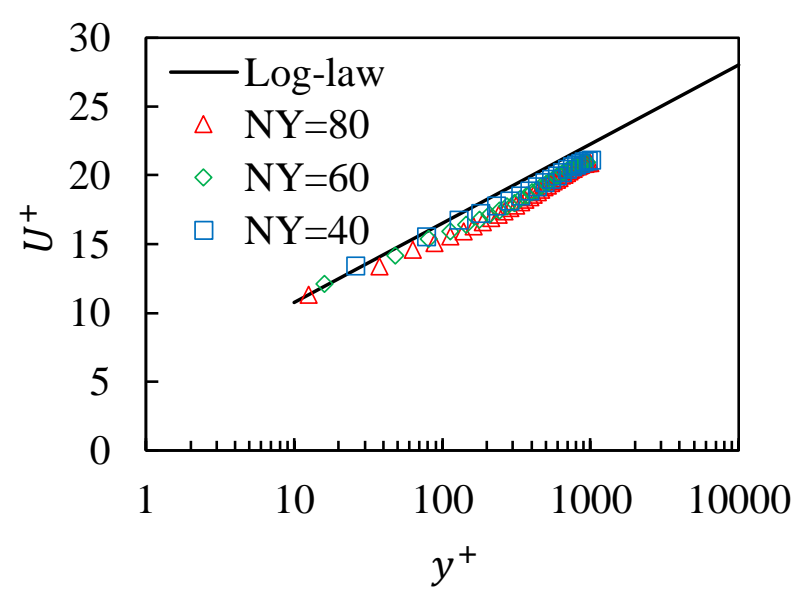

Fig. 3 Streamwise mean velocity at $\operatorname{Re}_{\tau}=1000$.

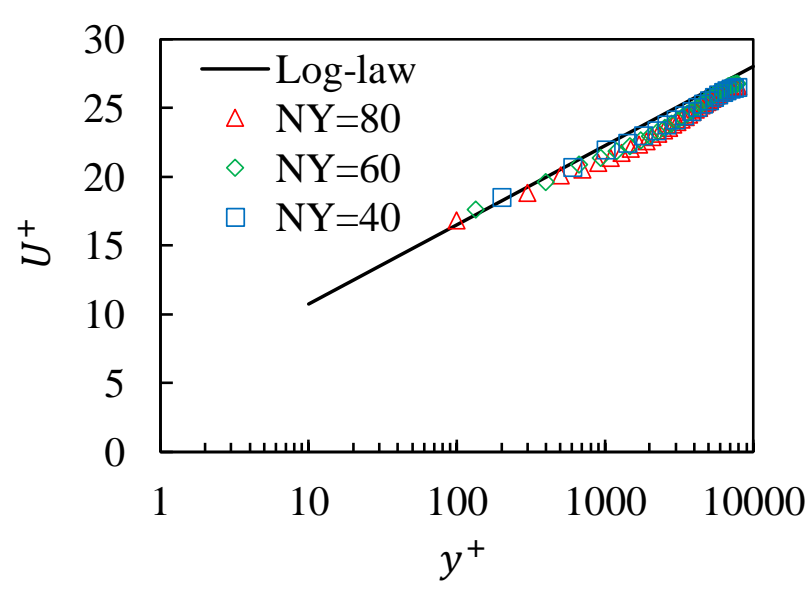

Fig. 5 Streamwise mean velocity at $\operatorname{Re}_{\tau}=8000$.

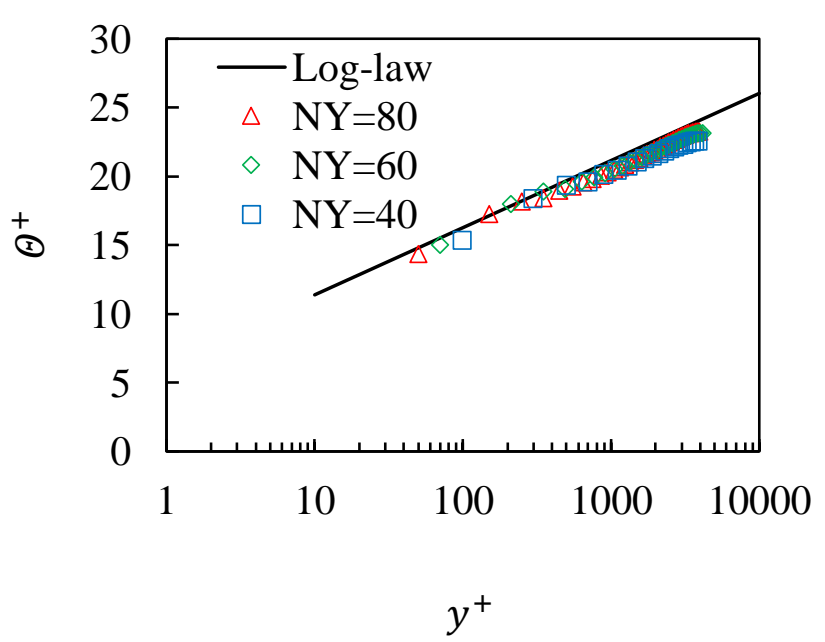

Fig. 7 Mean temperature at $\operatorname{Re}_{\tau}=4000$.

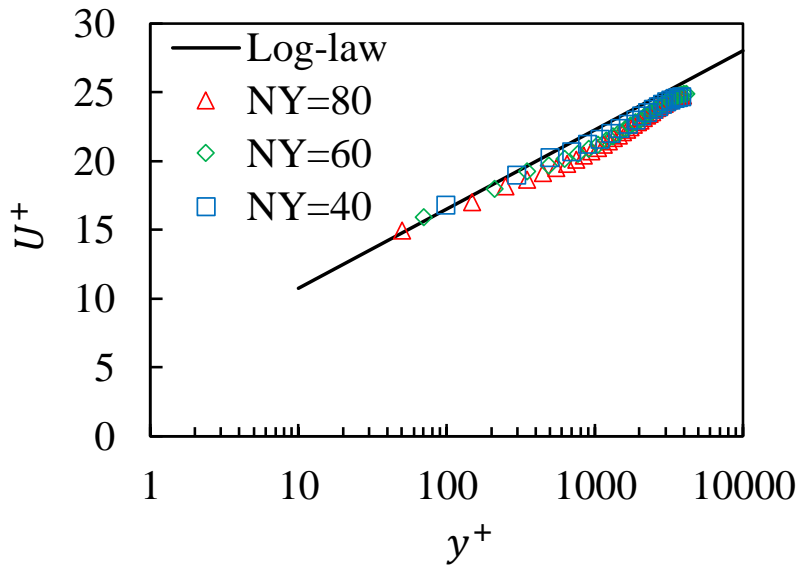

Fig. 4 Streamwise mean velocity at $\operatorname{Re}_{\tau}=4000$.

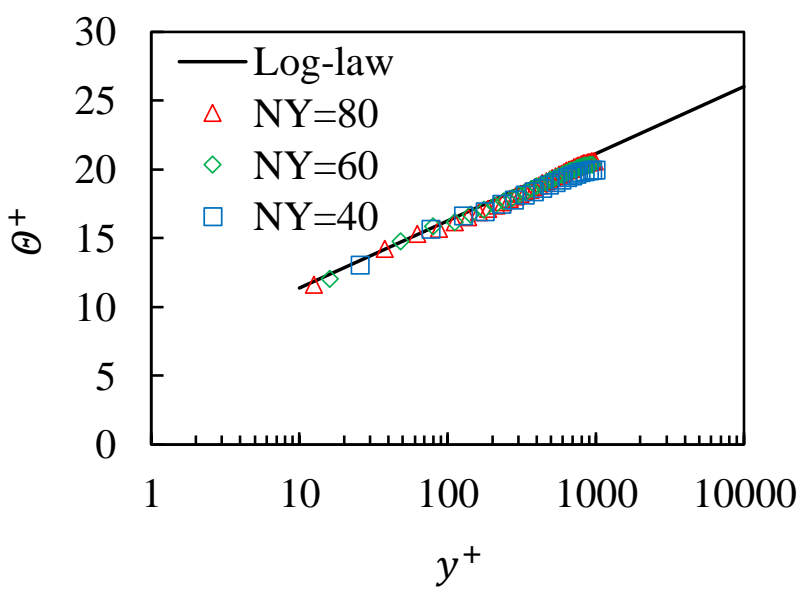

Fig. 6 Mean temperature at $\operatorname{Re}_{\tau}=1000$.

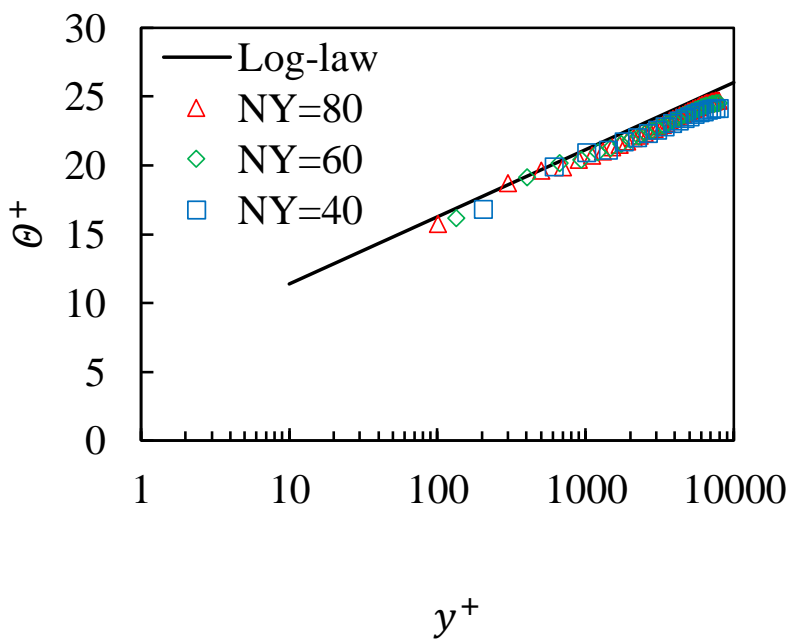

Fig. 8 Mean temperature at $\operatorname{Re}_{\tau}=8000$. 